\title{
Production of pomace olive oil
}

\section{By Pedro Sánchez Moral ${ }^{1}$ and $\mathbf{M}^{\mathrm{a}}$ Victoria Ruiz Méndez ${ }^{* 2}$}

\author{
${ }^{1}$ Oleícola el Tejar. Ntra. Sra. de Araceli, SCA. Benamejí (Córdoba) \\ 2 Instituto de la Grasa.CSIC. Avda. P. García Tejero, 4. 41012-Sevilla \\ *to whom correspondence should be addressed
}

\section{RESUMEN}

\section{Obtención de aceite de orujo}

El aceite de orujo es el principal subproducto en el procesado de aceite de oliva y su obtención se ha transformado considerablemente en los últimos tiempos debido a los avances tecnológicos que han experimentado las almazaras. Este trabajo tiene la finalidad de presentar una panorámica de la complejidad de este sector, de casi 100 años de existencia, que se afana en encontrar su función dentro de la nueva estrategia integral de la industria oleícola después de la crisis sufrida en el año 2001. En el mismo se comentan la extracción física, el secado, así como la extracción con disolvente, y la influencia que tienen los tratamientos tecnológicos sobre la composición química del aceite de orujo.

PALABRAS-CLAVE: Aceite de orujo - Extracción con solvente - Extracción física - Procesado - Secado.

\section{SUMMARY}

\section{Production of pomace olive oil}

Pomace oil is the principal by-product in olive oil processing and is currently developing considerably due to the technological advances which the mills have undergone in recent years. This investigation aims at presenting an overview of the complexity of this sector which, with around 100 years of existence, is searching for a role in the new integral strategy of the olive oil industry after the crisis suffered in 2001. Physical extraction, drying and solvent extraction are discussed, along with the influence of the technological treatments on the chemical composition of pomace oil.

KEY-WORDS: Drying - Physical extraction - Pomace olive oil - Processing - Solvent extraction.

\section{INTRODUCTION}

Olive pomace is the solid by-product obtained from the extraction of olive oil. It consists of pieces of skin, pulp, stone and olive kernel. Of the total olive weight, the pulp forms about $70-90 \%$, the stone $9-27 \%$ and the seed about $2-3 \%$. The removal of by-products from oil mills by pomace oil extractors totally solves the environmental problems caused by the olive oil production process. Similarly, the pomace oil extraction refining - bottling - distribution chain plays a decisive role in the economic activity of the sector (10\% of Spanish final agricultural production).
Until about 30 years ago, almost all olive oil was obtained through pressing. In the $70 \mathrm{~s}$, the mills gradually abandoned the traditional olive pressing process for economical reasons, because the method is labour intensive. Nowadays the traditional method is only used for processing small quantities of ecological olive oil. The alternative method is the continuous system works by means of the centrifugation of the beaten olive paste, producing three products: oil, pomace and residual water, just like the pressing system.

During the $90 \mathrm{~s}$, there was a major change in the raw material arriving at the olive pomace oil extractors. This was due to the fact that a large number of Spanish mills changed the olive oil continuous extraction equipment, converting from the three phase to the two phase system in order to optimize extraction costs and prevent the production of a highly polluting residual wastewater.

At present, three types of olive pomaces can be considered, depending on the extraction system used on the olive:

- Pomace from pressing.

- Pomace from the continuous system with centrifugal separation in three stages (oil, residual water and pomace), hereinafter referred to as "pomace from the three-phase process".

- Pomace from the continuous system with centrifugal separation in two stages: oil and solid waste (in which the olive vegetation water from the olive is absorbed, and olive mill wastewater is not produced since water is not required in the centrifugal process), hereinafter referred to as "two-phase pomace" (Alba et al., 1996).

The main differences between the extracted raw materials are due to water content. Two-phase pomace has moisture close to $70 \%$ and contains a certain amount of sugars as a result of the presence of vegetation water, while traditional pomace has a moisture content of between 25 and $30 \%$ in the pressing system, and $45 \%$ in 3 -phase centrifugal systems.

This leads to the need to modify the basic operations of transportation, storage and drying, making processing more expensive while at the same 
time reducing the profits rendered from fatty material. The changes produced in pressed olive pomace during storage were closely studied from either chemical (Gracian el al., 1961) or microbiological (Gracian et al., 1962 ) points of view.

According to the traditional method, pomace oil is extracted from a dried pomace $(8 \%$ moisture approximately) with solvent. The product obtained is the so-called "crude pomace oil".

On the other hand, if the fresh or stored two-phase pomace is subjected to a second centrifugation, it is possible to extract between $40-60 \%$ of the retained residual oil The process is carried out using horizontal centrifugal machines or decanters, (Alba et al., 1996). The oil obtained is known as "second centrifugation oil" and is commercially classified for its properties as "crude pomace oil".

Therefore, at present, two types of pomace oil are available: i) that extracted using solvents (traditional), ii) the oil obtained through physical extraction or centrifugation (second centrifugation).

The current pomace from the two phase centrifugal system, due to its high water content, is stored in ponds situated outside the factories, where it remains for up to 6 months, depending on the production capacity of the extractor.

The stored paste is of a heterogeneous nature and many chemical compounds coexist with the oil released. Among them are metals, alkaline (potassium) and alkaline-earth (calcium and magnesium), sugars and polyphenols, which come from the vegetation water. The properties of the oil obtained from this paste change as storage time increases, since the paste on the surface of the tank dries out. Quality deterioration is greater in oils from pastes which have been centrifuged twice and, in particular on the surface of the tanks or ponds, and therefore these containers should have the lowest possible surface area/volume ratio. (Ramos and Ruiz-Méndez, 2004).

In addition, free acidity increases with storage time in all cases, although it is higher in the paste taken from the top layer of the ponds. The concentrations of the compounds produced during fermentation of the paste also increases over time, with the appearance of methyl and ethyl esters, especially in pastes which have been subjected to a double centrifugation and stored for long periods of time (over two months) (Ramos and Ruiz-Méndez, 2004).

Pomaces from the traditional extraction system (pressure) and those from the three phase extraction require different preconditioning procedures than those coming from two phases pomaces prior to their extraction with solvent.

Figure 1 shows the block diagram of the treatment for pressed pomace or pomace from the three-phase process, where the pneumatically removal of the stone is done just after drying. The stone is separated, in the majority of cases, using separating machines where the air which flows against the pomace current pulls off the lighter pulp particles, leaving behind the heavier and larger stone pieces. To separate the pulp from the air flow which carries it, cyclones are used, which enable the air to be cleaned and emitted into the atmosphere. The pressed pomace and pomace from the three-phase process must be directly subjected to a drying process immediately after leaving the mills in order to prevent the rapid deterioration of the oil, particularly free acidity.

The other main difference between 3- phase pomace and alperujo (pomace from the two-phase process) lies in the method of removing the stone. Figure 2 shows the block diagram corresponding to the treatment of two-phase pomace in order to obtain oil from this residue by using solvents. Stone removal, as can be seen, is prior to drying and is carried out using mills with filters with approximately $3 \mathrm{~mm}$ spaces, which allow solids smaller than this size to pass through, expelling the larger stone directly to the drying phase. This provides greater yield in the physical extraction, reduced waste due to the metal parts which rub directly against the paste to be extracted and better exploitation of the resulting by-products.

Prior to separation by centrifugation, free of stone "alperujo" is then subjected to a malaxation process. The beating equipment is similar to that used in olive oil extraction. The temperature at which the centrifugation takes place is around $40^{\circ} \mathrm{C}$.

\section{PHYSICAL EXTRACTION USING CENTRIFUGATION}

The operating principle is similar to that for obtaining olive oil. Separation takes place in a horizontal cylindrical rotor with a worm screw. The pomace enters the rotor through an immobile input pipe and is driven ahead by an inner rotor. The centrifugal forces cause the solids to sediment on the rotor walls. The worm screw turns in the same

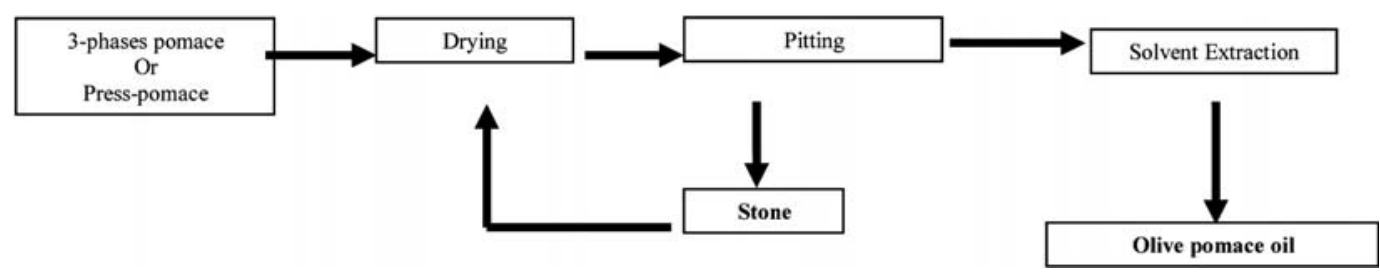

Figure 1

Block diagram of the oil production from pressed pomace or 3-phase pomace 


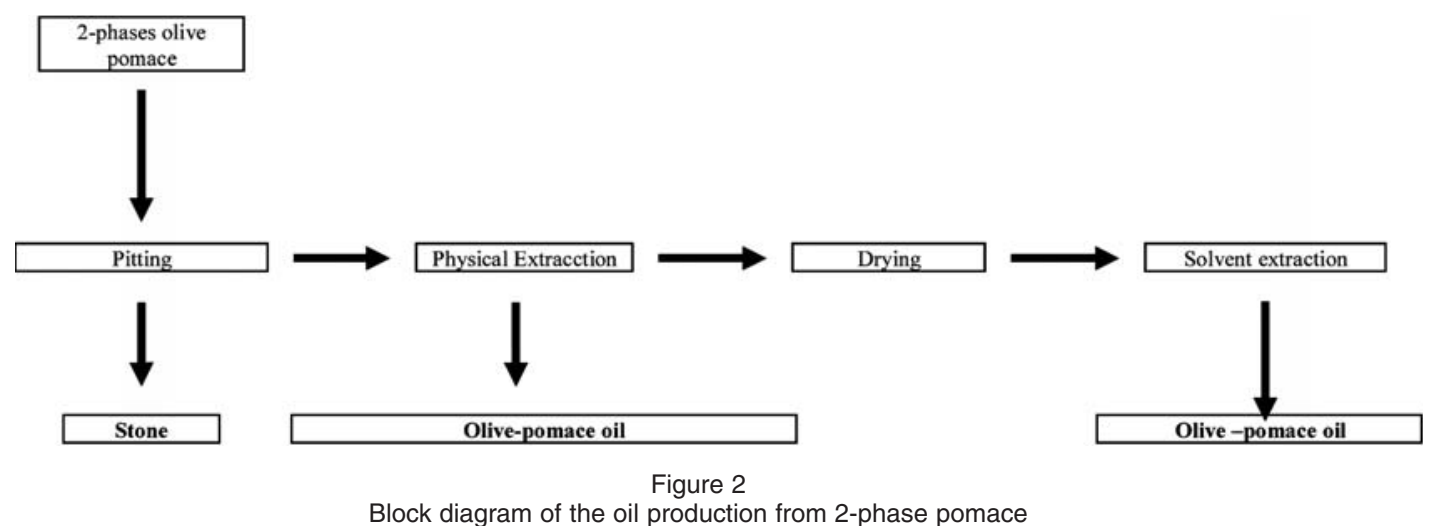

direction as the rotor, but at a different speed, making the solids move towards the conical end of the rotor. Separation takes place along the cylindrical part of the rotor, and the oil leaves the rotor through adjustable plates on the casing.

The extraction of this residual oil by centrifugation can be carried out in two or three phase systems depending on the capacity of the extractors for eliminating the residual water produced in three-phase centrifugation.

Three-phase centrifugation has the following advantages:

- It enhances the subsequent drying process, since at least $25 \%$ of the residual water contained in the "alperujo" is removed from the paste. This moisture decrease allows for the use of lower drying temperatures, which is favourable for obtaining an oil of better quality in the further chemical extraction.

- Major energy and financial savings are derived because the evaporation of the residual water in the evaporators/concentrators of the power plants takes place with zero net energy consumption. In fact, the process uses the residual energy of the exhaust steam from the turbine.

- It enables a residual water concentrate to be obtained, which is rich in mineral salts, sugars and polyphenols. This concentrate is of high commercial value due to its use as animal feed and organic-mineral fertilizer.

- The resulting residual water, "alpechin", is the departure point for obtaining compounds of high added value because they are beneficial to human health (Fki et al., 2005).

\section{DRYING}

This phase is compulsory for the extraction with hexane process, immiscible with water. This stage consumes a great amount of energy and is under continuous research with the objective of minimizing storage, residence times, energy costs, and to improving the quality of the obtained oil (Akgun and Doymaz, 2005; Freire et al., 2001; Gogus and Maskan, 2001).
Normally, drying takes place in rotary heat dryers (Espínola, 2003; Arjona et al., 1999, 2005) in which both the product (pomace) to be dried and the hot drying gases are introduced at high temperatures $\left(400\right.$ to $\left.800^{\circ} \mathrm{C}\right)$. When the pomace leaves the "trommel", it should have the appropriate moisture content.

The hot drying gases may come from a number of sources:

a) From the combustion of the residual exhausted olive cake which is obtained after the extraction with solvents of the dry fatty pomaces. This is a more widely-used fuel, but it is also the most polluting due to the emission of fine particles produced in the combustion. These fine particles are swept away by the drying gases.

b) From the combustion of stones. This material may come either from the pomace paste itself after the drying phase, or from the previous centrifugation before the physical extraction phase. Due to the low ash content of these stones and the type of combustion, this material is very efficient, in terms of heat, cost and environmental impact. These pieces of stones have found important markets outside, with their exportation being very active. This demand has increased its price, which is nowadays rather high and has markedly decreased its application for thermal purposes. It should be noted that the olive stones have several important advantages:

- It is an annually renewable fuel with zero net contribution to the greenhouse effect.

- It is not subjected to market fluctuations because the material is produced in the same plants where it is consumed. Thus, its price does not depend on the international market for fossil fuels.

- Its combustion produces hot gases in a stable range of temperatures, which may reach up to $800^{\circ} \mathrm{C}$.

- With careful control of the combustion, the drying gases broadly comply with European Legislation for gaseous pollutants. 
c) The drying gases can also come from the exhausted gases from a turbine or gas engine in a cogeneration process of electricity using natural gas. Obviously, this installation must be close to the drying installation. In recent years, in order to increase profitability, some of such cogeneration plants have made agreements with drying plants for selling them the exhausted gases from their turbines or engines. Alternatively, they have created joint enterprises for this business. From an environmental point of view, the use of these gases is the cleanest system for drying pomace. However, they have two main disadvantages:

- Natural gas is a non-renewable fossil fuel, which is subject to huge market fluctuations. Unexpected high prices for the gas can seriously affect the economic viability of the plants.

- The hot gases produced never exceed $500^{\circ} \mathrm{C}$. This circumstance makes the enlargement of the drying facilities necessary. On the other hand, the low temperature of the hot gases produces better quality chemically extracted oil.

The most important element of the drying process is the drying drum, a "trommel", which consists of a rotary cylinder supported on rolling strips. A toothed sprocket and two rollers control its rotation. The rotation speed depends on the size of the cylinder. The cylinder may be a single or a double passage drier. In the double passage driers, there are two concentric cylinders where the exterior cylinder is supported by the interior one which, in turn, is supported on the rolling strips. There are a series of blades in the interior of the inner cylinder which ensure that the pomace comes into contact with the hot gas flow. They also impulse the pomace to move forward.

Inside the drum, the hot gasses transfer their heat to the water contained in the olive pomace, which is evaporated. The gasses and the steam are then put in contact with fresh material until them al cooled to below $100^{\circ} \mathrm{C}$.

The gasses are evacuated from the drum, together with the produced steam, through cyclones, by an induced draught fan. In addition, this device produces a light vacuum in the drum. Before being emitted to the atmosphere these gases are passed through highly efficient cyclonic decanters which remove the fine particle in suspension and make them suitable for emission, as can be deduced from Table 1 .

The oil reflects the thermal aggression to which it is submitted by developing brown colours, due to the alteration of the double bonds of the hydrocarbonate chains, and the formation of triglyceride dimers and polymers. Drying also produces an increase in the concentration of oxidized compounds, significantly higher K232 values, and oxidized triglycerides, which increase by $35 \%$. (Gomes and Capornio, 1997)

The strong drying process which was applied after the first appearance of the of two-phase pomace caused the formation of an unusually high quantity of Polycyclic Aromatic Hydrocarbons (PAHs), possibly due to the polymerization of the sugars at temperatures above $400^{\circ} \mathrm{C}$ and the direct effect of combustion fumes on the material to be dried (LeónCamacho et al., 2003; Guillén et al., 2004).

Depending on the degree of humidity at the entrance to the dryer, different drying processes can be chosen. At present there are basically three types of drying:

\section{Single stage direct drying}

This type of single stage dryer is ideal for pomace cake, 3-phase pomace and two-phase pomace when this has previously passed through the dehydrated physical extraction stage in three phases. This drying system can also be used for 2phase pomace which does not need to be totally dried, as required for chemical extraction, but will be used as fuel in cogeneration plants with biomass for producing electricity.

\section{Two stage direct drying}

This system is ideal for pomace from the threephase process which is to be dried at low temperatures in order to improve the quality of the oils obtained in the chemical extraction step. It is also highly suited to drying 2-phase olive pomace where the first drying stage reduces the humidity to below $50 \%$ and the second further reduces it to around $10 \%$, as required for a good chemical extraction.

Direct drying in one stage with recirculation of dried pomace and prior mixing.

This system is highly advisable for two-phase pomace, when humidity, after stone removal and

Table 1

Percentage composition of gases emerging from drying process

\begin{tabular}{lc}
\hline Compounds & Percentage (\% wt/wt) \\
\hline Steam $\left(\mathrm{H}_{2} \mathrm{O}\right)$ & 36,40 \\
Carbon dioxide $\left(\mathrm{CO}_{2}\right)$ & 11,40 \\
Nitrogen $\left(\mathrm{N}_{2}\right)$ & 47,69 \\
Oxigen $(\mathrm{O} 2)$ & 4,48 \\
\hline From: DPTO. INGENIERIA QUIMICA DE LA UCO
\end{tabular}

From: DPTO. INGENIERIA QUIMICA DE LA UCO 
physical extraction, is above $70 \%$. The advantage of the procedure lies in the recirculation of part of the dried pomace which leaves the dryer. This material is then mixed with damp olive pomace. The mixture is, therefore assimilated to a pomace from the three-phase process with moisture content below $50 \%$ at the entrance to the dryer. The mixture then follows a similar process to that of pomace coming from the 3-phase process, permitting an increase in dryer yield and production.

\section{CHEMICAL EXTRACTION WITH SOLVENT}

Chemical extraction with solvents is achieved in three phases: preparation of the fatty pulp, extraction with hexane, desolventization of the extracted pulp and distillation of the fatty miscella (Ortega et al., 2001).

However, after the drying process, the pomace requires certain preparation in order to maximize the extraction efficiency. This is due to the fact that the dried pulp is not appropriate for direct extraction. The main problem is related to the extremely low percolation. Therefore, the treatments have the objective of preparing the pulp so that an increase in solvent penetration into the solid layer could be obtained. This preparation will, therefore, facilitate oil extraction and the subsequent desolventization and extractors' unloading.

This preparation is made by granulating the pulp with machinery which is used, among other uses, in the granulation of compound animal feedingstuffs. However, the fatty "pulp" is not easily granulated due to its high oil content. To improve the conditions of the process, a suitably -sized mesh, $(6 \times 60 \mathrm{~m} / \mathrm{m})$ should be selected, and steam should be used in small quantities as compacting agent. However, the use of large quantities of steam is detrimental because, then, the humidity content of the granule will increase, and this will negatively affect the subsequent extraction.

In the former discontinuous extractors stones are still used to increase percolation. In general, if the "granulated pulp" fractions and the stone fragments are going to be remixed for extraction, the degree of compaction is less important than when only the granulated pulp fraction is extracted. In this case, a certain level of compromise is required, enabling good percolation, desolventization and discharging together with good drainage.

The advantage of submitting only the correctly granulated pulp to extraction is that the material submitted to extraction is richer in fat. This, in turn, leads to solvent and energy savings as well as an increase in distillation and extraction capacity because the granulated pulp contains, at least, $15 \%$ less inert material than if it also contained stones. To achieve this, the pulp must be correctly separated from the stone fragments, which should be sufficiently clean to ensure that the oil content in stones is below $2 \%$.
The extraction with solvent (chemical extraction) process may be achieved in three different types of extractors:

\section{Discontinuous}

These are extractors with simple contact equipment, where both the extraction and the distillation of the resultant miscella are carried out in a discontinuous or batch format. They are no longer used for economic, technical or safety reasons.

\section{Semi-continuous}

This is the most generalized system in the pomace oil sector. In this case, extraction is made through the gradual enrichment of the miscella, using a system of multiple contacts with fixed layers. In other words, the fresh solvent is introduced into the tank where the solid is most drained in fat, flowing through the different tanks and leaving the system through the most recently filled tank. This takes place in discontinuous extractors but the distillation process is continuous. The system is made up of a series of cylindrical extractors consisting of loading and discharging nozzles, hexane or miscella inputs and steam input for the desolventization. There is also an air output. The extractor itself operates as an extractor and desolventizer. The extractors are loaded with fatty pomace in pellet form from an upper hopper. The exhausted olive cake is discharged under pressure after desolventization. As there are several extractors in the system, the unit is similar to a continuous extractor in that, while one is filling up, others are at the washing with hexane or enriched miscella stage and another is at the desolventization and discharge stage.

There are a number of manufacturers of semicontinuous extractors differing only in size, in the number of extractors installed and the continuous or semi-continuous distillation system installed. Other differences are insignificant.

\section{Continuous}

In this system, the basic operation of solid-liquid extraction is carried out through multiple contacts in counter current. The input and the solvent enter the extraction stage system at opposite ends. With the system of multiple contacts against the flow, the solid is gradually impoverished in fats from the first to the final stage, while the hexane miscella is gradually enriched from the last to the first stage. The separation efficiency in this type of operation is greater than in the other forms of contact.

Most frequently used in the industry are continuous moving solid layer and percolation extractors. The most notable differences between the different suppliers are in the system unit or the extraction unit, which is made up of three basic sections: a) Extraction of oil, and b) Desolventization of pulp - cooling, and, c) Distillation and recovery of solvent 
The efficiency of the best-known extractors (DE SMET, ROTOCEL, LURGI, CROWN, EX TECHNIK) is similar. The differences lie in other aspects, such as: construction quality, knowledge of the raw material, technical service, operating and safety system facilities.

The authorized solvent for the extraction of fats is n-hexane. Its main advantages are selectivity, extraction power, almost zero influence on the oil quality, physical properties, (latent heat of vaporization, boiling temperature $\left(60^{\circ} \mathrm{C}\right)$, steam tension) and chemical properties (low corrosive action).

Certainly, the extraction stages that have suffered major evolution and have been subjected to more conceptual changes with respect to their basic design in recent years have been desolventization and cooling. The reasons behind this pressure for new developments are demands for a decrease in energy and hexane consumption, in addition to questions of safety in storage and transportation.

To remove the hexane retained in the solid, a desolventizer is used: it consists of a vertical column made up of various cylindrical trays, each of which has a double base heated by steam.

The solvent simply evaporates in the heat into a dry atmosphere in the upper trays.

A direct jet of steam is used on the lower trays to remove the majority of the residual solvent from the exhausted olive cake (Peña et al., 2003). The exhausted olive cake is usually dried and cooled on additional trays located below those used in the desolventization process.

Distillation is the process which separates the components of the dissolution, exploiting the different boiling points of the micelle components through the addition of sufficient heat for the component with the lowest boiling point to distil. Moreover, the addition of heat is combined with the action of a vacuum unit, allowing the temperatures reached to be lower than would be necessary under atmospheric conditions, thus at the same time managing to increase the energy performance of the process and its efficiency.

The purpose of the distillation of the miscella is to separate, by evaporation, the solvent from the oil which remains liquid throughout the operation. The following points should be observed during the process: a) the hexane should be recovered in order to reincorporate it into the process. b) The oil should be free of hexane in order to prevent risk in the subsequent processing (storage and refining). The oil should be in the distillation unit for as short a time as possible, only as long as necessary for the finished product to be lower than $150 \mathrm{ppm}$ of hexane in oil.

Finally, hexane leaks should be avoided, not only for safety reasons due to the formation of explosive atmospheres, but also because the concentration of hexane saturation in the air is high and increases with temperature.

Taking into consideration the fact that in Andalusia there is a large extraction industry, every possible effort is made to ensure that measures are taken to reduce levels of Organic Solvent consumption which currently stand at 6000 t/year compared to $1500 \mathrm{t} /$ year under the National Plan for the Reduction of Annual Emissions of VOCs

\section{PROPERTIES OF CRUDE POMACE OIL}

In addition to the above mentioned changes occurring in the oil during the storage of raw materials in ponds, differences are also observed in other components of interest due to both physical and chemical processing.

It is already known that the extraction of oils becomes extremely difficult when the proportion of oils in the pomace to be extracted is below $2 \%$. In addition, the oil extracted is of notably inferior quality. One might assume that this is due to the fact that the solvent basically extracts lipidic compounds from the cellular membranes, such as phospholipids and waxes, given that the triglycerides retained in the cell vacuoles, in our particular case, have already been separated for the most part in successive centrifugations.

This, in turn, makes the properties of the oil, extracted with solvent from the dry solid material of the two-phase pomace, very different with respect to the quality of pomace oil obtained from the three phase system. The crude pomace oil extracted with solvent coming from those materials, which are stored wet, presents a greater quantity of phospholipids, waxes and a significant quantity of anomalous compounds. Table 2 shows, as an example, the free acidity, and the phosphorous, soap and ethyl ester content in samples of crude pomace oil (Martin, 2000).

In comparison with olive oil, in the case of pomace oil, Spanish and European Regulations permit higher values for those parameters which are indicative of chemical changes (trans fatty acids, saturated fatty acids in the beta position of the triglyceride, ultraviolet absorption, etc) than the levels authorized for olive oil. As mentioned above, these changes occur principally as a result of the pomace drying process.

Crude olive oil showed a phenolic profile similar to that of virgin olive oil, with aglycons of hydroxytyrosol and tyrosol prevailing. In contrast, the second-centrifugation oil and the crude pomace oil had a high concentration of simple phenols such as hydroxytyrosol, tyrosol, vanillic acid, vanillin, $p$ coumaric acid, and the lignans 1-acetoxypinoresinol and pinoresinol.

A new compound was found in secondcentrifugation oil, which is mainly responsible for its foul door. It was identified as 4-ethylphenol. Although 4-ethylphenol was discovered in all oils intended for refining, its presence was particularly significant in "second centrifugation oil", its concentration increasing with storage time of the olive paste. Similar trends were observed for hydroxytyrosol, hydroxytyrosol acetate, tyrosol, and catechol, the concentration of these substances reaching values 
Table 2

Characteristics of oil samples extracted from 2-phase olive pomace

\begin{tabular}{ccccc}
\hline Sample & $\begin{array}{c}\text { Acidity } \\
\text { (\% Oleic) }\end{array}$ & $\begin{array}{c}\text { Phosphorous } \\
\text { (ppm) }\end{array}$ & $\begin{array}{c}\text { Soaps } \\
\text { (ppm) }\end{array}$ & $\begin{array}{c}\text { Alkyl Esters } \\
(\%)\end{array}$ \\
\hline A & 7,30 & 479 & 41496 & 3,27 \\
B & 2,39 & 357 & 543 & 0,18 \\
C & 7,45 & 446 & 19492 & 1,41 \\
D & 3,36 & 332 & 455 & 0,23 \\
E & 11,20 & 432 & 27120 & 3,25 \\
F & 8,81 & 432 & 24160 & 1,86 \\
G & 14,47 & 454 & 40303 & 2,72 \\
H & 12,43 & 443 & 2257 & 0,83 \\
I & 18,57 & 486 & 3776 & 1,6 \\
J & 14,78 & 486 & 6913 & 1,92 \\
\hline
\end{tabular}

(Martin, 2000)

of up to $600 \mathrm{mg} / \mathrm{kg}$ of oil, which makes their recovery for food, cosmetic, or pharmaceutical purposes attractive.

In contrast to the high concentration in polyphenols in fresh or stored "alperujo", the extracted with solvent material had a very low amount of these substances, hydroxytyrosol, its acetate, and lignans being the most representative. In addition, analyses of the phenolic extracts did not detect secoiridoid aglycons in these oils. (Brenes et al., 2004)

In summary, these compounds and the derivatives arising from alterations during wet storage of the two-phase pomace have a major influence on the refining process. In fact, traditional refining methods had to be modified for obtaining similar oil quality to those from three-phase systems.

\section{INTEGRAL EXPLOITATION OF THE BYPRODUCTS}

The exploitation of "alperujo" from an environmental point of view may be approached in a number of ways, such as composting, (Alburquerque et al., 2004; Giannoutsou et al., 2004) gasification (Ollero et al. 2003), steam explosion treatment for obtaining hydroxytyrosol (Fernandez Bolaños et al., 2003) or the extraction of oils (Clemente et al. 1997) as presented above. The by-products generated are the stone, the fat-free solid (or exhausted olive cake) and the residual wastewater.

In addition to their use as fuel, with the properties discussed above, stone are also used as abrasive material for cleaning walls, for example, in the manufacturing of furfural, and for the manufacturing of active carbon for the treatment of gases, water or other special applications.

The traditional use of exhausted olive cake is as fuel in drying ovens or steam boilers because of its thermal capacity. As mentioned above, the pomace oil extraction industry is a high energy consumer, particularly at the pomace drying stage and during extraction with solvent. This fact, together with the imbalance currently existing in Spain between the generation of and increasing demand for electrical energy has led the sector to propose electrical cogeneration projects, such that, by exploiting the calorific potential of the exhausted olive cake or the alperujo (biomass), it is possible to generate electrical energy and exploit the residual thermal energy for the stages of drying and extraction with solvent (Figure 3).

Similarly, the ashes produced in combustion are used to manufacture manures, given their high soluble potassium content.

And finally, what is perhaps the newest use of olive mill wastewater, complex agro industries are integrally exploiting the pomace with evaporators/concentrators capable of removing the olive mill wastewater and exploiting the residual energy of the exhaust steam from electricity generating turbines. The liquid generated in this process is used as cooling water in the capacitors and the resulting concentrate is excellent for use in the manufacturing of manures and fertilizers, and for its use as animal feed.

\section{REFERENCES}

Akgun NA, Doymaz I. 2005. Modelling of olive cake thinlayer drying process. J. Food Engineering 68, 455-461. Alba Mendoza, J, Hidalgo Casado F, Ruiz Gómez MA Martínez Román F, Moyano Pérez MJ, Cert Ventulá A, Pérez-Camino M C, Ruiz-Méndez MV. 1996. Características de los aceites de oliva de primera y segunda centrifugación. Grasas y Aceites 47, 163-181.

Alburquerque JA, Gonzalvez J, García D, Cegarra J. 2004. Agrochemical Characterisation of "alpeorujo", a solid by-product of the two-phase centrifugation method for olive oil extraction. Bioresource Technology 91, 195-200.

Arjona R, García A, Ollero P. 1999. The drying of alpeorujo, a waste product of the olive oil mill industry. J. Food Engineering 41, 229-234. 


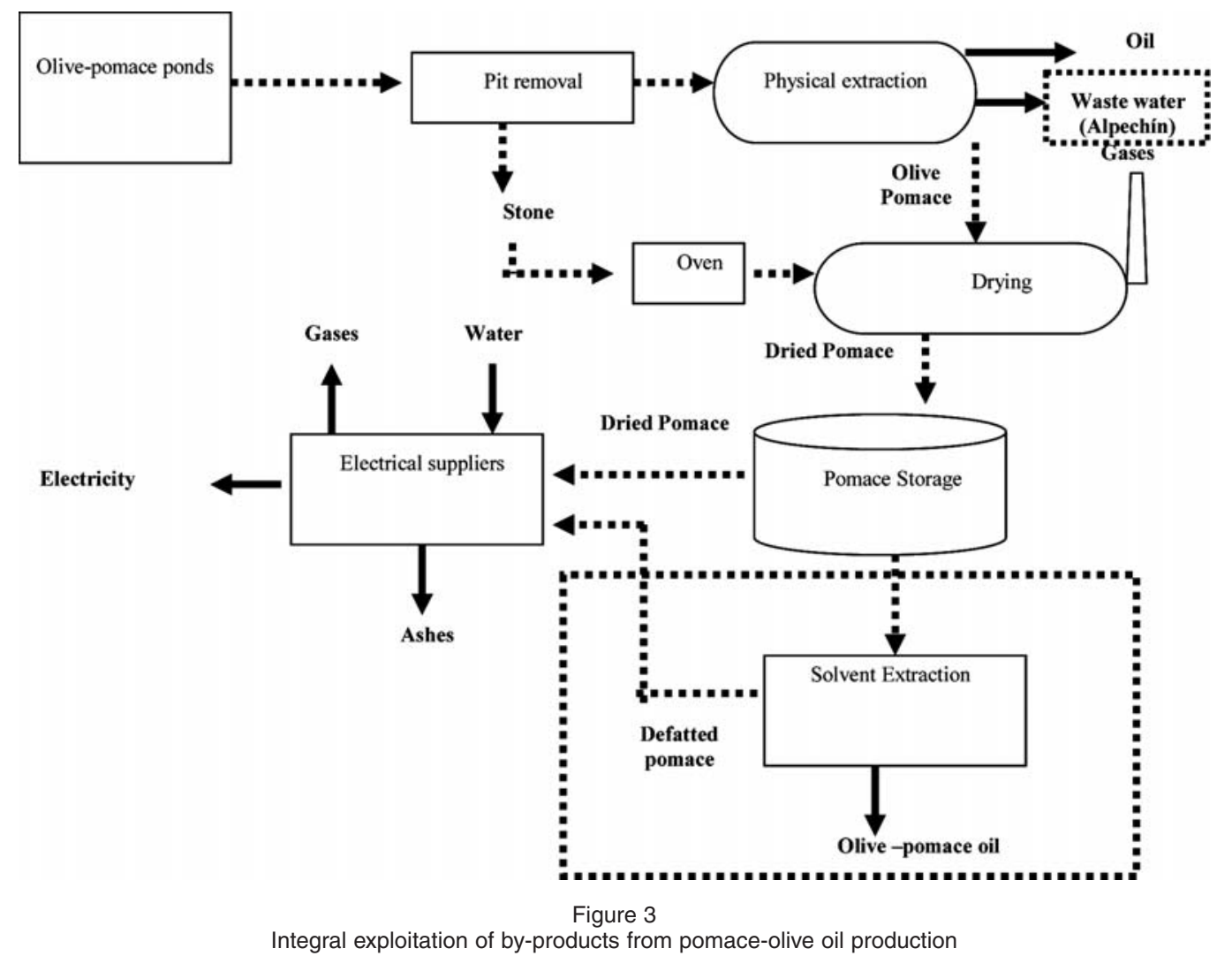

Arjona, R, Ollero P, Vidal, BF. 2005. Automation of an olive waste industrial rotary dryer. J. Food Engineering 68, 239- 247.

Brenes M, Romero C, García A, Hidalgo FJ, RuizMéndez MV. 2004. Phenolic compounds in olive oils intended for refining: formation of 4-ethylphenol during olive paste storage. J. Agric.Food Chem. 52, 8177-8181.

Clemente A, Sánchez-Vioque R, Vioque J, Bautista J, Millan F. 1997. Chemical composition of extracted dried olive pomaces containing two and three phases. Food Biotechnology 11, 273-291.

Espínola-Lozano F. 2003. Technological change in the extraction of olive pomace oils. Alimentación Equipos y Tecnología 22, 60-64.

Fernaández Bolaños J, Heredia A, Rodríguez Gutierrez G, Rodríguez R, Jiménez A, Guillén R. Method for obtaining purified hidroxitirosol from products and byproducts derived from olive tree. EU Patent $N^{\circ} 1369$ 407 A1 (10-10-2003)

Freiré F, Figueiredo A, Ferrao P. 2001. Modelling high temperature-thin layer-drying kinetics of olive bagasse. J. Agric. Eng. Res. 78, 397-406.

Fki I, Allouche N, Sayadi S. 2005. The use of polyphenolic purified hydroxytyrosol and 3,4-dihydroxyphenyl acetic acid from olive mill wastewater for the stabilization of refined oils: a potential alternative to synthetic antioxidants. Food Chemistry 93 ,

Giannoutsou EP, Meintanis C, Karagouni AD. 2004. Identification of yeast strains isolated from a twophase decanter system olive oil waste and investigation of their ability for its fermentation. Bioresource Technology 93,301-306.
Gogus F, Maskan M. 2001. Drying of olive pomace by a combined microwave-fan assisted convection oven. Nahrung 45, 129-132.

Gomes T, Capornio F. 1997. Evaluation of the state of oxidation of crude olive-pomace oils. Influence of olive-pomace drying and oil extraction with solvent. J. Agric. Food Chem. 45, 1381-4

Guillen, MD, Sopelana, P, Palencia G. 2004. Polycyclic aromatic hydrocarbons and olive pomace oil. J. Agric. Food Chem. 52, 2123-2132.

Gorbuz, S. 2004. Through process modifications for selected SMbs in production. J. Cleaner Production 12, 613-621.

Gracián J, Arevalo G, Albi T. 1961. Alteraciones del orujo graso de la aceituna durante su almacenamiento. I. Transformaciones Químicas. Grasas y Aceites 12, 174-9.

Gracián J, González-Cancho F. Arevalo G. 1962. Alteraciones del orujo graso de la aceituna durante su almacenamiento. II. Aspectos microbiológicos. Grasas y Aceites 13, 17-27.

Lesage-Meessena L, Navarro D, Maunier S, Sigoillot JC, Lorquin J, Delattre M, Simón JL, Asther M, Labal M. 2001. Simple phenolic content in olive oil residues as a function of extraction systems. Food Chemistry 75, 501-507.

León-Camacho M, Viera-Alcaide I, Ruiz-Méndez MV. 2003. Elminatíon of polycyclic aromatic hydrocarbons by bleaching of olive pomace oil. European J. Lipid Sci. Techn. 105, 9-16.

Martin JL, 2000. Personnel communication.

Ollero P, Serrera A, Arjona R, Alcantarilla S. 2003. The $\mathrm{CO} 2$ gasification kinetics of olive residue. Biomass and Bioenergy 24, 151 - 161. 
Ortega A, Palomar JM, Mata JE, Cruz F, Montoro V. 2001. Automatic control of extractors. Alimentación Equipos y Tecnología 20, 139-149.

Peña F, Cárdenas S, Gallego M, Valcarcel M. 2003. Direct sampling of orujo for determining residual hexane by using a ChemSensor. J. Am. Oil Chem. Soc. 80, 613-618.

Ramos-Hinojosa A, Ruiz-Méndez MV. 2004.Orujo de dos fases almacenados en balsas. Grasas y Aceites 55, 251-258.

Regalement (CEE) $N^{\circ} 2458 / 91$ relative to the characteristics of olive oil and its methods of analysis and its modifications in the regalement 796/2002. Official
Diary of the European Community. (15 May 2002) LI128 p. 8-13.

Ruiz-Méndez MV, Ramos Hinojosa AE. 2003. Fatty acid esters with short-chain alcohols in two-phase olive pomace oils. Europ. J. Lipid Sci. Techn.105, 346-350.

Vlyssides AG, Loizides M, Karlis PK. 2004. Integrated strategic approach for reusing olive oil extraction byproducts. J. Cleaner Prod. 12, 603-611.

Recibido: Septiembre 2005 Aceptado: Noviembre 2005 